\title{
Harmonics Analysis of Power Electronics Loads
}

\author{
Srijan Saha, Suman Das \\ M.Tech. Final Year Student \\ Dept. of Electrical Engineering \\ Tripura University
}

\author{
Champa Nandi \\ Assistant Professor \\ Dept. of Electrical Engineering \\ Tripura University
}

\begin{abstract}
The linear customer loads are now being dominated by sensitive and sophisticated non-linear customer loads with the growth in the power electronics and control system industries. This have a catastrophic impact on a power system and equipment: increasing harmonics "pollution". In this paper the modelling of power electronics loads used in domestic and small scale industrial distribution systems are discussed. Various domestic loads such as computer, fluorescent lamp, CFL lamp and small scale industry loads such as adjustable speed drive, arc welder and lift are modelled in PSCAD/EMTDC and then the harmonic analysis of these models are performed
\end{abstract}

\section{Keywords}

Power Quality, Harmonics, Total Harmonic Distortion (THD), Current harmonics, industrial system, Power Elactronics Load.

\section{INTRODUCTION}

The power quality of the electrical power is one of the important factors that hurdle to deliver power to all customers in a safe, reliable and economical mode. The voltage, current and frequency of as the electric power should be in specific range so that it results in normal operation of customer equipment, defined as power quality [3]. However, in practice it is difficult to achieve this situation [3]. For the people working in different fields the power quality means different things.

a) For a quality engineer the power quality means a sinusoidal waveform of distribution bus voltage at rated voltage and frequency.

b) For a customer it means the absence of large voltage variation, outages, sags, surges, harmonics and flickers as measured at the point of service.

c) For a manufacturer it means equipment compatibility with the supply of electric power.

In ideal world the term harmonics referred to Power quality, would mean how pure the voltage and the current waveform are in their sinusoidal form [3]. Harmonic distortion is not a new phenomenon on power systems. Harmonic distortion was very less in the past when the designs of power systems were very simple and conservative [3]. But, nowadays the electronic equipments became more powerful and versatile, used in commercial, industrial and residential installations. As a result harmonic distortion has increased as well and power quality problems resulting from harmonics have been getting more and more attention by researchers [3].

In this paper the effects of Harmonics in the Power System are explained and also explained how Harmonic distortion is one of the most important problems associated with power quality and creates several disturbances to the Power System.
The effect of nonlinear loads ranging from adjustable speed drives, to house hold appliances, such as Fans with Electronic Regulators on the utility voltage and current harmonics are also discussed. Some of the commonly used power electronics loads those are used in domestic and industrial systems are modeled in PSCAD/ EMTDC and then the harmonic analysis of these models are performed.

\section{HARMONICS}

\subsection{Definition of Harmonics}

A harmonic is defined as a sinusoidal component of a periodic wave or quantity having a frequency that is an integral multiple of the fundamental frequency [3]. For example, if a component frequency is twice of the fundamental frequency is called the second harmonic [3]. Thus, on a $50 \mathrm{~Hz}$ power system, a harmonic component $\mathrm{h}$ is a sinusoid having a frequency expressed by the following [3]:

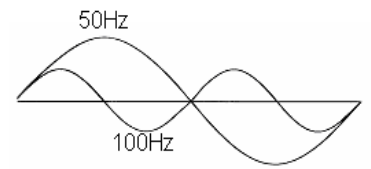

$2^{\text {nd }}$ Harmonic $(100 \mathrm{~Hz})$

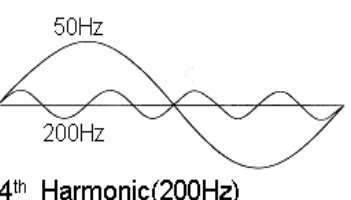

$4^{\text {th }}$ Harmonic $(200 \mathrm{~Hz})$

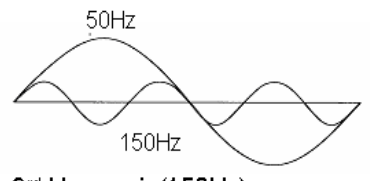

$3^{\text {rd }}$ Harmonic $(150 \mathrm{~Hz})$

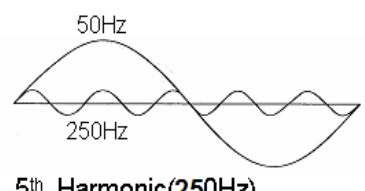

$5^{\text {th }}$ Harmonic $(250 \mathrm{~Hz})$
Figure 1: Harmonics [3]

Sinusoidal waves that are not an integral multiple of the fundamental are not harmonics but are defined in terms of the fundamental as per-unit frequencies [3].

\subsection{Characteristics of Harmonic Currents}

Power conversion using full wave rectifiers generates idealized characteristic harmonic currents given by the formula [1]:

$$
\mathrm{h}=\mathrm{x} \cdot \mathrm{p} \pm 1
$$

Where,

$$
\begin{aligned}
& \mathrm{h}=\text { order of harmonics } \\
& \mathrm{x}=\text { an integer } 1,2,3 \ldots \\
& \mathrm{p}=\text { number of current pulses per cycle }
\end{aligned}
$$




\subsection{Calculation of Voltage Distortion}

The instantaneous value of voltage for non-sinusoidal waveform or complex wave can be expressed as [1]:

$$
\begin{aligned}
\mathrm{V}= & \mathrm{V}_{0}+\mathrm{V}_{1} \sin \left(\omega \mathrm{t}+\varphi_{1}\right)+\mathrm{V}_{2} \sin \left(2 \omega \mathrm{t}+\varphi_{2}\right) \\
& +\ldots \mathrm{V}_{\mathrm{n}} \sin \left(\mathrm{n} \omega \mathrm{t}+\varphi_{\mathrm{n}}\right)
\end{aligned}
$$

Where,

$$
\begin{aligned}
& \mathrm{V}=\text { instantaneous value at any time } \mathrm{t} \\
& \mathrm{V}_{0}=\text { direct (or mean) value (DC component) } \\
& \mathrm{V}_{1}=\text { rms value of the fundamental component } \\
& \mathrm{V}_{2}=\text { rms value of the second harmonic component } \\
& \mathrm{V}_{\mathrm{n}}=\text { rms value of the nth harmonic component } \\
& \Phi=\text { relative angular frequency } \\
& \omega=2 \pi \mathrm{f} \\
& \mathrm{f}=\text { frequency of fundamental component }
\end{aligned}
$$

The rms value of voltage and current can be expressed as [1]:

$$
\begin{aligned}
\mathrm{V}_{\mathrm{rms}}=\sqrt{\frac{1}{T} \int_{0}^{T} v^{2}(t) d t} & =\sqrt{\sum_{h=1}^{\infty} V_{h}^{2}} \\
& =\sqrt{V_{1}{ }^{2}+V_{2}{ }^{2}+V_{3}{ }^{2} \ldots+V_{n}{ }^{2}} \\
\mathrm{I}_{\mathrm{rms}}=\sqrt{\frac{1}{T} \int_{0}^{T} i^{2}(t) d t} & =\sqrt{\sum_{h=1}^{\infty} I_{h}^{2}} \\
& =\sqrt{I_{1}{ }^{2}+I_{2}{ }^{2}+I_{3}{ }^{2} \ldots \ldots+I_{n}{ }^{2}}
\end{aligned}
$$

The rms voltage or current "total harmonic distortion", $\mathrm{V}_{\text {thd }}$ and $\mathrm{I}_{\text {thd }}$, respectively can be expressed as:

$\mathrm{V}_{\text {thd }}=\frac{\sqrt{\sum_{h=2}^{\infty} V_{h}^{2}}}{V_{1}} \times 100 \%=\frac{\sqrt{V_{2}^{2}+V_{3}^{2}+V_{4}^{2} \ldots \ldots+V_{n}^{2}}}{V_{1}} \times 100 \%$

$\mathrm{I}_{\mathrm{thd}}=\frac{\sqrt{\sum_{h=2}^{\infty} I_{h}^{2}}}{I_{1}} \times 100 \%=\frac{\sqrt{I_{2}^{2}+I_{3}^{2}+I_{4}^{2} \ldots \ldots+I_{n}^{2}}}{I_{1}} \times 100 \%$

\subsection{Harmonic Sequence Components}

Each harmonic has an order (number), a frequency which is an integer multiple of the fundamental frequency and a "sequence" [1]. The sequence refers in vector rotation with respect to the fundamental [1].

Table 1 details the harmonic sequence components for an idealized 6-pulse rectifier [1].

Table 1. Harmonic Sequence Components for 6-Pulse Rectifier [1]

\begin{tabular}{|l|l|l|l|l|l|l|l|l|l|}
\hline Harmonic & 1 & 5 & 7 & 11 & 13 & 17 & 19 & 23 & 25 \\
\hline Sequence & + & - & + & - & + & - & + & - & + \\
\hline Rotation & F & B & F & B & F & B & F & B & F \\
\hline
\end{tabular}

Harmonics such as the 7 th, $13^{\text {th }}$ and 19 th, and so on, which rotate in a forward direction are termed "positive sequence harmonics" whereas the 5th, 11th, and so on, which rotate in the opposite direction to the fundamental are termed "negative sequence harmonics" [1]
Triplen harmonics (3rd, 9th...), as produced in single-phase full wave rectifiers, for example, do not rotate [1]. They are in phase with each other and are therefore termed "zero sequence harmonics" [1].

\subsection{Inter-harmonics}

Inter-harmonics are defined in IEC Standard 1000-2-1 as: "Between the harmonics of the power frequency voltage and current, further frequencies can be observed, not an integer of the fundamental [1]. They appear as discrete frequencies or as a wide-band spectrum"[1].

Due to the modulation of steady state harmonic voltages, the supply voltage will vary in amplitude and rms value according to

$v(t)=\sin \left(2 \pi f_{1} t\right)+a \sin \left(2 \pi f_{i} t\right)$

Where,

$$
\begin{aligned}
& \mathrm{f}_{1}=\text { fundamental frequency } \\
& \mathrm{a}=\text { amplitude of the inter-harmonics voltage } \\
& \mathrm{f}_{\mathrm{i}}=\text { inter-harmonics frequency }
\end{aligned}
$$

The rms voltage value can be given by:

$\mathrm{V}=\sqrt{\frac{1}{T} \int_{0}^{T} V(t)^{2} d t}$

Where, the period of integration $T=1 / f_{1}$

\subsection{Sub-harmonics}

"Sub-harmonics" is an unofficial but common definition given to inter-harmonics whose frequency is less than that of the fundamental (i.e., $\mathrm{f}>0 \mathrm{~Hz}$ and $\mathrm{f}<\mathrm{f}_{1}$ ) [1].

\subsection{Problem associated with Harmonics interface}

Some problem those are associated with the harmonic interface are as follows [6]:

i. Increase losses both in the supply and within supply transformer.

ii. Nuisance tripping of circuit breakers.

iii. Premature ageing of electrical insulation.

iv. Malfunctions or failure of some electrical circuits

v. Certain type of metering can be subject to erroneous operation De-rating of fuses due to the heat generated by harmonics during normal operation.

vi. Possible cause of system resonance when power factor correction equipment is present on the system. This occurrence can impose high voltages currents on the system which is most undesirable.

vii. Premature failure of power factor correction / capacitor installations.

\subsection{Harmonics Impacts}

In electrical power system harmonic distortion causes various problems towards the electric generation systems, transmission networks and end users in the distribution level [6]. Performance or reliability problems of equipments, over voltage problems, unstable operation of zero voltage crossing firing circuits, overheating neutral conductors and transformers and communication interferences are some of the current problems that's are found from harmonic distortion due to power electronic equipments [6]. 
The problems caused will concurrently have impact on metering devices, nuisance tripping of circuit breakers, uncomfortable flickering of fluorescent lights, miss-operation of relays, mal-operation of important controls and others [6].

A number of undesirable effects are there on power system equipments and loads due to harmonics. These fall into two basic categories [6]:

i. Shorts-term - usually the most noticeable and are related to the excessive voltage distortion.

ii. Long-term - often go undetected and are usually related to increased resistive losses or voltage stresses.

\subsection{Sources of Harmonics}

The power electronics equipments that produce harmonics in the power system are comes from the daily equipments we use [1].

\subsection{Fundamental and harmonic power}

The product of in phase current times the voltage is power, or

$\mathrm{P}_{\text {fundamlental }}=\mathrm{V}_{\text {fundamental }} \cdot \mathrm{I}_{\text {fundamental }} \cdot \cos \theta_{1}$

It is also the in-phase harmonic current times the harmonic voltage, in case of harmonics, or

$\mathrm{P}_{\text {harmonic }}=\mathrm{V}_{\text {harmonic }} \cdot \mathrm{I}_{\text {harmonic }} \cdot \cos \theta_{\text {harmonic }}$

The harmonic currents flowing through the resistance of the circuit represent a power loss as

$\mathrm{P}_{\mathrm{h}}=\mathrm{I}_{\text {harmonic }} \cdot \mathrm{R}_{\text {harmonic }}$

$\mathrm{R}_{\mathrm{h}}$ can vary with applied harmonics because of skin effect, stray currents, eddy currents, etc [3].

\section{MODELING OF POWER ELECTRONICS LOADS}

Computer simulation is the most convenient way of harmonic analysis provided that the system components are modeled accurately and verified either through measurements or mathematically. This section presents the simulation models for water pump and arc furnace and FFT analysis results of some of the commonly used domestic \&industrial loads are given in Table $2 \& 3$

\subsection{Water Pump}

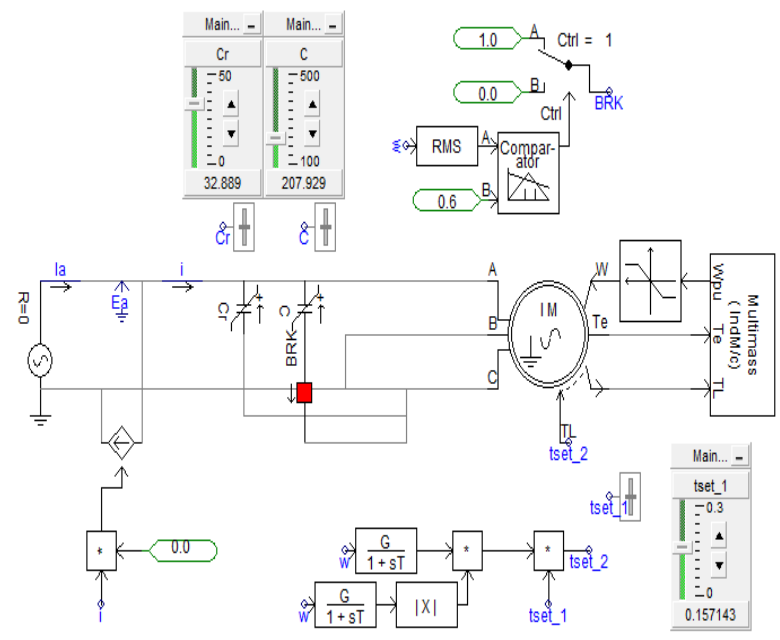

Figure 2: Simulation of Water Pump model in PSCAD/EMTDC

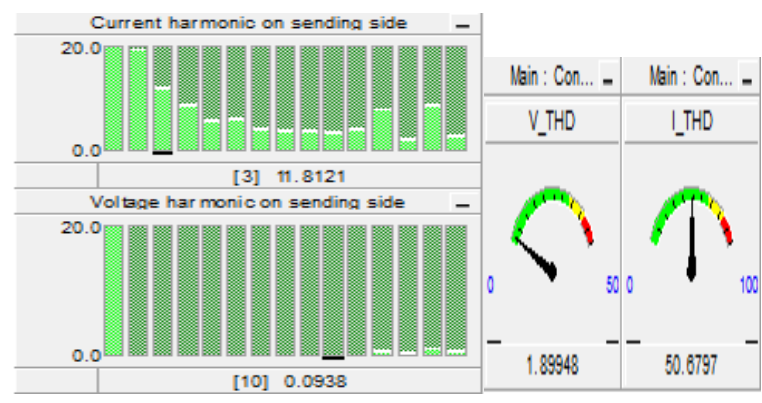

Figure 3: FFT analysis of Water Pump

\subsection{Arc Furnace}

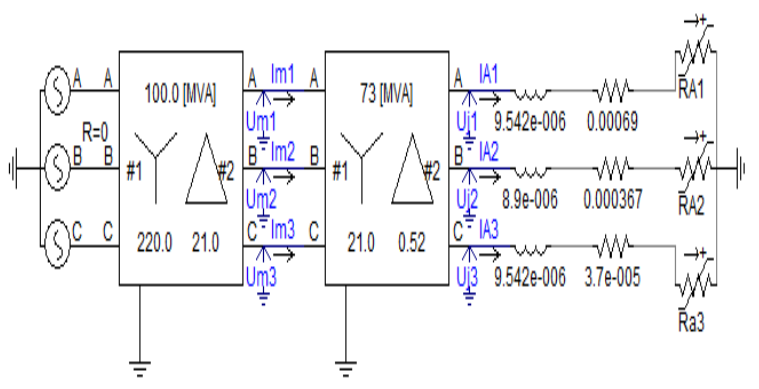

Figure 4: Simulation Arc Furnace model in PSCAD/EMTDC

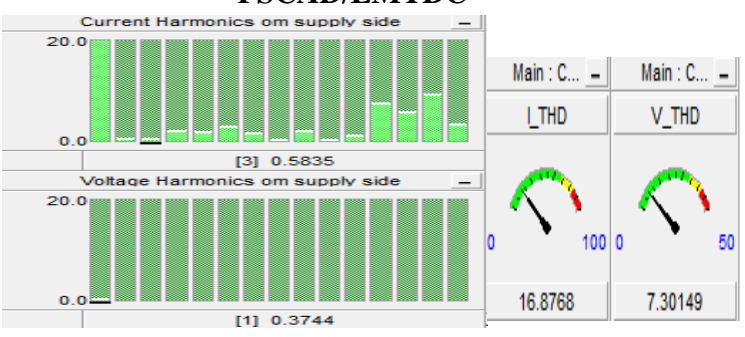

Figure 5: FFT analysis of Arc Furnaces 


\section{RESULT DISCUSSION}

FFT analyses of the harmonic on the supply side of the different power electronics loads are found.

The Water Pump current has mostly effected by $95.84 \%$ of $2^{\text {nd }}$ order harmonic, $59.06 \%$ of $3^{\text {rd }}$ order harmonic and $44.11 \%$ of $14^{\text {th }}$ order harmonic shown in Figure 3. The Arc Furnaces current has mostly effected by $17.73 \%$ of $13^{\text {th }}$ order harmonic, $16.52 \%$ of $15^{\text {th }}$ order harmonic and $13.96 \%$ of $6^{\text {th }}$ order harmonic are shown in Figure 5.

Table 2. Simulation Results of Load Current and THDs for power electronics Loads

\begin{tabular}{|c|c|c|c|c|}
\hline Sl. No. & Equipment Name & Simulated $\mathbf{I}_{\text {rms }}(\mathbf{A})$ & $\mathbf{T H D}_{\mathbf{V}}(\boldsymbol{\%})$ & $\mathbf{T H D}_{\mathbf{I}}(\mathbf{\%})$ \\
\hline 1 & Computer Monitors & 0.374 & 3.331 & 91.224 \\
\hline 2 & Battery Charger & 3.068 & 3.286 & 29.521 \\
\hline 3 & Fluorescent Lamp & 0.471 & 3.224 & 44.596 \\
\hline 4 & CFL & 15.899 & 1.899 & 50.679 \\
\hline 5 & Water Pump & 6.179 & 1.899 & 13.422 \\
\hline 6 & ASD & 0.042 & 5.873 & 27.888 \\
\hline 7 & Lift Motor & 9.593 & 1.085 & 16.876 \\
\hline
\end{tabular}

Table 3.FFT Analysis Result for all Individual power electronics Loads

\begin{tabular}{|c|c|c|c|c|c|c|c|c|c|c|}
\hline \multicolumn{3}{|c|}{ Sl. No } & 1 & 2 & 3 & 4 & 5 & 6 & 7 & 8 \\
\hline \multicolumn{3}{|c|}{ Equipment Name } & $\begin{array}{l}\text { Computer } \\
\text { Monitors }\end{array}$ & $\begin{array}{l}\text { Battery } \\
\text { Charger }\end{array}$ & $\begin{array}{l}\text { Fluorescent } \\
\text { Lamp }\end{array}$ & CFL & $\begin{array}{l}\text { Water } \\
\text { Pump }\end{array}$ & ASD & $\begin{array}{c}\text { Lift } \\
\text { Motor }\end{array}$ & $\begin{array}{c}\text { Arc } \\
\text { Furnace }\end{array}$ \\
\hline $\begin{array}{l}\mathbf{H} \\
\mathbf{a}\end{array}$ & \multirow{7}{*}{ Odd } & $\begin{array}{c}3^{\text {rd }} \\
\text { order }\end{array}$ & 67 & 38.4 & 64.99 & 47.3 & 59.06 & 1 & 0.002 & 2.92 \\
\hline $\begin{array}{l}\mathbf{r} \\
\mathbf{m}\end{array}$ & & $\begin{array}{c}5^{\text {th }} \\
\text { order }\end{array}$ & 25 & 7.8 & 64.99 & 27.9 & 28.69 & 6 & 20.8 & 8.6 \\
\hline $\begin{array}{l}\mathbf{n} \\
\mathbf{i}\end{array}$ & & $\begin{array}{c}7^{\text {th }} \\
\text { order }\end{array}$ & 7 & 5.6 & 63.7 & 19.55 & 21.05 & 3 & 8.6 & 7.75 \\
\hline c & & $\begin{array}{c}9^{\text {th }} \\
\text { order }\end{array}$ & 0.05 & 2.6 & 63.8 & 14.85 & 20.11 & 1.8 & 0.12 & 9.58 \\
\hline \multirow{10}{*}{$\begin{array}{c}\mathbf{C} \\
\mathbf{u} \\
\mathbf{r} \\
\mathbf{r} \\
\mathbf{r} \\
\mathbf{r} \\
\mathbf{e} \\
\mathbf{n} \\
\mathbf{t} \\
(\boldsymbol{\%})\end{array}$} & & $\begin{array}{l}11^{\text {th }} \\
\text { order }\end{array}$ & 0.03 & 2 & 61.5 & 11.8 & 20.92 & 1.97 & 7.46 & 5.77 \\
\hline & & $\begin{array}{c}13^{\text {th }} \\
\text { order }\end{array}$ & 0.021 & 1.2 & 60.35 & 9.1 & 10.73 & 2.35 & 5.2 & 17,73 \\
\hline & & $\begin{array}{c}15^{\text {th }} \\
\text { order }\end{array}$ & 0.022 & 0.28 & 70.95 & 4.7 & 12.38 & 0.07 & 2.3 & 16.52 \\
\hline & \multirow{7}{*}{ Even } & $\begin{array}{c}2^{\text {nd }} \\
\text { order }\end{array}$ & 0.335 & 54.6 & - & 0.433 & 95.84 & 0.006 & 0.009 & 2.99 \\
\hline & & $\begin{array}{c}4^{\text {th }} \\
\text { order }\end{array}$ & 0.292 & 21.8 & - & 0.393 & 43.9 & 0.01 & 0.009 & 10.45 \\
\hline & & $\begin{array}{c}6^{\text {th }} \\
\text { order }\end{array}$ & 0.168 & 1.56 & - & 0.332 & 31.4 & 0.001 & 0.007 & 13.98 \\
\hline & & $\begin{array}{c}8^{\text {th }} \\
\text { order }\end{array}$ & 0.085 & 5.16 & - & 0.257 & 18.78 & 0,009 & 0.009 & 2.26 \\
\hline & & $\begin{array}{c}10^{\text {th }} \\
\text { order }\end{array}$ & 0.014 & 0.32 & - & 0.177 & 18.01 & 0 & 0.007 & 1.81 \\
\hline & & $\begin{array}{c}12^{\text {th }} \\
\text { order }\end{array}$ & 0.09 & 2.24 & - & 0.149 & 38.68 & 0 & 0.005 & 3.75 \\
\hline & & $\begin{array}{c}14^{\text {th }} \\
\text { order }\end{array}$ & 0.092 & 0.2 & - & 0.258 & 44.11 & 0 & 0.014 & 4.594 \\
\hline
\end{tabular}

Table 3 lists the \% of odd and even order harmonics present in supply current of all other individual power electronics loads, obtained after FFT analysis. Table 2 lists the THDs of voltage and current due to the power electronics loads obtained from simulation result. The load current is also specified. These THDs are calculated based on the individual load ratings, as 
given in Table 4. We can see that the THD values and the \% of harmonics founded in supply current are crossing the limits as compare to the IEC 61000-3-2 Standard and IEEE 5191992 Standard [7].

Table 4. Ratings of Domestic and Industrial Loads Modeled in PSCAD

\begin{tabular}{|c|c|c|}
\hline Sl.No. & Domestic Load & Ratings \\
\hline 1 & CFL lamp & $20 \mathrm{~W}$ \\
\hline 2 & Fluorescent Lamp & $40 \mathrm{~W}$ \\
\hline 3 & Water pump & $5 \mathrm{~kW}, 6 \mathrm{~A}$ \\
\hline 4 & Computer Monitor & $100 \mathrm{~W}$ \\
\hline 5 & Battery Charger & $12 \mathrm{~V}, 3 \mathrm{~A}$ \\
\hline 6 & Adjustable speed drive & 3-phase, $400 \mathrm{~V}, 10 \mathrm{hP}$ \\
\hline 7 & Lift Motor & 46.3kW,62hP,9A \\
\hline 8 & Arc Furnace & 3-phase ,400V,25.4 \\
& & MW \\
\hline
\end{tabular}

\section{CONCLUSION}

In this paper the modeling of power electronics loads used in domestic such as TV/CPU, Battery Charger and small scale industrial distribution systems such as ASD, Lift motor are modeled and simulated using PSCAD/EMTDC Software. Harmonics present in power electronics loads are founded by performing FFT analysis and $\mathrm{THD}_{\mathrm{V}}$ and $\mathrm{THD}_{\mathrm{I}}$ values are also founded. From this analysis it is concluded that the TV \& PC monitor \& CFL current has been mostly effected by $3^{\text {rd }}$ order harmonic, the battery charger \& water pump current has been mostly effected by $2^{\text {nd }}$ order harmonic, the Fluorescent Lamp current has been mostly effected by all odd order harmonics, the ASD \& lift motor current has been mostly effected by $5^{\text {th }}$ order harmonic, the arc furnaces current has been mostly effected by $17.73 \%$ of $13^{\text {th }}$ order harmonic.

\section{REFERENCES}

[1] "Guidance Note On Control of Harmonics in Electrical Power Systems" May 2006.

[2] Johan Lundquist, "On Harmonic Distortion in Power Systems".

[3] Raneru Nageswara Rao, "Harmonic Analysis of Small Scale Industrial Loads and Harmonic Mitigation Techniques in Industrial Distribution System," in IJERA, Vol. 3, Issue 4, Jul-Aug 2013, pp.1511-1540.

[4] Dr. Mike Mehrdad and Dr. E.K.Stanek and Dr. A.S. Jannati,"Influence of Voltage and Current Harmonics on Behavior of Electric Devices".

[5] "www.pscad.com."

[6] Siti Saleha Binti Abas, "Simulation of Harmonic Currents and Voltages Due to Power Electronic Equipments" May 2006.

[7] Srijan Saha, Champa Nandi, "Modelling and Harmonic Analysis of Domestic/Industrial Loads," in National Seminar on Energy Science and Engineering (NSESE2013), Nov 29-30,2013. 